\section{Review: inhaled anticholinergics increase risk of major cardiovascular events in COPD}

\section{QUESTION}

In patients with chronic obstructive pulmonary disease (COPD), do inhaled anticholinergics increase risk of major cardiovascular events?

\section{REVIEW SCOPE}

Included studies compared an inhaled anticholinergic with placebo or active drugs in patients with COPD and reported serious cardiovascular adverse events. Outcomes were a composite cardiovascular end point (non-fatal myocardial infarction, non-fatal stroke [including transient ischaemic attack], or cardiovascular death [including sudden death]), its components, and all-cause death.

\section{REVIEW METHODS}

Medline (Mar 2008), Cochrane Database of Systematic Reviews, websites of the US Food and Drug Administration and European regulatory authorities, clinicaltrials.gov, drug company product information sheets and clinical trials registers, reference lists, and Web of Science Citation Index were searched for English-language, published or unpublished, randomised controlled trials (RCTs) with $>30$ days of followup. 17 RCTs ( $n=14783$, mean age 49-68 y, 58-99\% men) met the selection criteria. The anticholinergic was tiotropium in 12 RCTs and ipratropium in 5 RCTs. The comparator was placebo in 9 RCTs, salmeterol in 5 RCTs, salmeterol plus fluticasone in 2 RCTs, and albuterol in 1 RCT. All trials were double-blind, and 4 trials reported adequate allocation concealment. Duration of follow-up ranged from 6 to 26 weeks in 12 short-term trials and from 48 weeks to 5 years in 5 long-term trials.

\section{MAIN RESULTS}

Inhaled anticholinergics increased risk of the composite end point, myocardial infarction, and cardiovascular death, but not stroke or all-cause death (table). Inhaled anticholinergics increased risk of the composite end point in the 5 long-term trials ( $\mathrm{n}=7267$, relative risk [RR] 1.7, 95\% CI 1.3 to 2.4 ) but not in the 12 short-term trials $(n=7516$, RR 1.2 , CI 0.67 to 2.0).

\section{CONCLUSION}

In patients with chronic obstructive pulmonary disease, longterm use of inhaled anticholinergics increases risk of major cardiovascular events.

Abstract and commentary also appear in ACP Journal Club.

\section{ABSTRACTED FROM}

Singh S, Loke YK, Furberg CD. Inhaled anticholinergics and risk of major adverse cardiovascular events in patients with chronic obstructive pulmonary disease: a systematic review and meta-analysis. JAMA 2008;300:1439-50.

Correspondence to: Dr S Singh, Wake Forest University School of Medicine, Winston-Salem, NC, USA; sosingh@wfubmc.edu

Source of funding: no external funding.

- Clinical impact ratings: IM/Ambulatory care 6/7; Respirology 6/7; Cardiology 5/7

Inhaled anticholinergics $v$ placebo or active drugs (control) in patients with chronic obstructive pulmonary disease*

\begin{tabular}{|c|c|c|c|c|c|}
\hline \multirow[b]{2}{*}{ Outcomes } & \multirow[b]{2}{*}{ Number of trials (n) } & \multicolumn{2}{|c|}{ Weighted event rates } & \multicolumn{2}{|c|}{ At 6 weeks to 5 years } \\
\hline & & Anticholinergics & Control & RRI $(95 \%$ CI) & NNH (CI) \\
\hline Major cardiovascular event $\dagger$ & 17 (14 783) & $1.9 \%$ & $1.2 \%$ & $58 \%(21$ to 106$)$ & 147 (80 to 404$)$ \\
\hline Myocardial infarction & $11(10598)$ & $1.3 \%$ & $0.8 \%$ & $53 \%$ (5 to 123$)$ & 228 (98 to 2410 ) \\
\hline Stroke & 7 (9251) & $0.6 \%$ & $0.4 \%$ & $46 \%(-19$ to 162$)$ & Not significant \\
\hline Cardiovascular death & 12 (12 376) & $0.9 \%$ & $0.5 \%$ & $80 \%(17$ to 177$)$ & 250 (113 to 1177$)$ \\
\hline All-cause death & 17 (14 783) & $2.0 \%$ & $1.6 \%$ & $26 \%(-1$ to 61$)$ & Not significant \\
\hline
\end{tabular}

*Abbreviations defined in glossary. Weighted event rates, RRI, NNH, and $\mathrm{Cl}$ calculated from data in article using a fixed-effect model.

$\uparrow$ Myocardial infarction, stroke, or cardiovascular death. he review by Singh et al and the trial by Tashkin et al were done to address uncertainty about the risks and benefits of inhaled anticholinergic therapy in COPD. However, understanding the discrepant findings is a challenge. Why did the meta-analysis show a $53 \%$ increase in myocardial infarction and a $26 \%$ increase in all-cause mortality with inhaled anticholinergics, whereas the subsequent large UPLIFT trial found relative reductions of $27 \%$ and $11 \%$ with tiotropium for these same outcomes?

Contradictory findings may reflect differences in individual trial characteristics. No trial was designed with mortality or cardiovascular events as a primary outcome. Most trials had high dropout rates that differed between groups, creating substantial opportunity for biased estimation of treatment effects, especially for secondary outcomes. However, mortality data for the UPLIFT trial were $98 \%$ complete, whereas no other long-term tiotropium trial collected mortality data after patients withdrew. Also, the UPLIFT trial followed patients for 4 years, allowing capture of more events than previous shorter trials. As a striking illustration, the UPLIFT trial reported deaths in $15.7 \%$ of participants compared with $1.8 \%$ in the meta-analysis.

Singh et al's decision to pool placebo-controlled trials with trials using active comparators is questionable. Absence of statistical heterogeneity among trials provides insufficient reassurance if there is a high index of suspicion that other drugs have effects on the end points of interest. Consequently, the meta-analysis findings could reflect differing efficacy of these active agents for reducing cardiovascular events. However, the UPLIFT trial uniquely permitted other COPD therapies as cointerventions, many of which were excluded in other trials. Thus, it remains possible that inhaled anticholinergics increase risk of cardiovascular events when given alone but not when combined with an inhaled corticosteroid (ICS) and long-acting $\beta$ agonist (LABA). In addition, the extent to which patients in the placebo group of the UPLIFT trial received short-acting anticholinergic medications is not completely clear.

Commentary continued on next page 


\section{Tiotropium reduced exacerbations but not rate of $\mathrm{FEV}_{1}$ decline in patients with COPD using other respiratory medications}

\section{STUDY DESIGN}

Design: randomised placebo-controlled trial (Understanding Potential Long-Term Impacts on Function with Tiotropium [UPLIFT]). ClinicalTrials.gov NCT00144339.

Allocation concealment: concealed. ${ }^{*}$

Blinding: blinded (clinicians, patients, data collectors, and outcome adjudication committee). *

\section{STUDY QUESTION}

Setting: 490 centres in 37 countries worldwide.

Patients: 5993 patients $\geqslant 40$ years of age (mean age $65 \mathrm{y}, 75 \%$ men) who had COPD, a history of $\geqslant 10$ pack-years of smoking, and postbronchodilation $\mathrm{FEV}_{1} \leqslant 70 \%$ of predicted and $\leqslant 70 \%$ of FVC. Exclusion criteria included a history of asthma or pulmonary resection, recent COPD exacerbation or respiratory infection, and use of supplemental oxygen for $\geqslant 12$ hours/day.

Intervention: inhaled tiotropium, $18 \mu \mathrm{g}$ once daily $(n=2987)$, or placebo $(n=3006)$. Additional use of any respiratory medication, except other inhaled anticholinergic drugs, was allowed.

Outcomes: primary outcomes were rate of decline in mean $\mathrm{FEV}_{1}$ before and after use of the study drug and a short-acting bronchodilator from day 30 until the end of treatment. Secondary outcomes included health-related quality of life (St George's Respiratory Questionnaire, range 0-100 [worst]), COPD exacerbations, all-cause mortality, and adverse events.

Follow-up period: 4 years.

Patient follow-up: 59\% of patients completed the trial. About $81 \%$ of patients were assessed for $\mathrm{FEV}_{1}$ and quality of life; 98\% were followed for mortality (intention-to-treat analysis).

\section{MAIN RESULTS}

Mean $\mathrm{FEV}_{1}$ value was higher in the tiotropium group than in the placebo group at all time points, by $87-103 \mathrm{ml}$ before bronchodilation and by $47-65 \mathrm{ml}$ after bronchodilation. Groups did not differ for rate of decline in mean $\mathrm{FEV}_{1}$ (table). Mean quality-of-life score was an average 2.7 units (95\% CI 2.0 to 3.3) better in the tiotropium group, but rate of decline did not differ between groups. At 4 years, the hazard ratio for first COPD exacerbation with tiotropium compared with placebo was 0.86 (CI 0.81 to 0.91 ; number needed to treat 19 , CI 13 to 29$\} \dagger$ ) and for all-cause mortality was 0.89 (CI 0.79 to 1.02). Relative risk of myocardial infarction was 0.73 (CI 0.53 to 1.0 ) and of stroke was 0.95 (CI 0.70 to 1.3 ).

\section{CONCLUSION}

In patients with chronic obstructive pulmonary disease, most of whom were using long-acting $\beta$-agonists and inhaled steroids, tiotropium improved quality of life and reduced exacerbations but did not reduce rate of decline in $\mathrm{FEV}_{1}$.

*See glossary.

†Calculated from data in article.

Abstract and commentary also appear in ACP Journal Club.

\section{ABSTRACTED FROM}

Tashkin DP, Celli B, Senn S, et al. A 4-year trial of tiotropium in chronic obstructive pulmonary disease. N Engl J Med 2008;359:1543-54.

Correspondence to: Dr D P Tashkin, University of California, Los Angeles, Los Angeles, CA, USA; dtashkin@mednet.ucla.edu

Source of funding: Boehringer Ingelheim and Pfizer.

- Clinical impact ratings: IM/Ambulatory care 6/7; Respirology 6/7; GP/FP/Primary care $5 / 7$

Inhaled tiotropium $v$ placebo for chronic obstructive pulmonary disease

\begin{tabular}{|c|c|c|c|c|}
\hline \multirow[b]{2}{*}{ Outcomes at 4 years } & \multirow[b]{2}{*}{ Mean baseline value (I) } & \multicolumn{2}{|c|}{ Mean decline (ml/year) } & \multirow[b]{2}{*}{ Difference in means $(95 \% \mathrm{Cl})^{*}$} \\
\hline & & Tiotropium & Placebo & \\
\hline $\mathrm{FEV}_{1}$ before bronchodilation & 1.09 & 30 & 30 & $0(-4$ to 4$)$ \\
\hline
\end{tabular}

${ }^{*} \mathrm{Cl}$ defined in glossary.

\section{Commentary continued from previous page}

Nevertheless, the UPLIFT trial provides important reassurance that tiotropium, added to usual COPD therapy, does not increase cardiovascular events or mortality. Although an updated meta-analysis incorporating the UPLIFT trial would be helpful, it would be dominated by UPLIFT's findings because its total events vastly outnumber those of all other trials combined. However, such a meta-analysis would be useful in helping us understand the extent to which chance can explain differences in study findings.

The finding of the UPLIFT trial that adding tiotropium in patients already receiving an ICS-LABA combination further reduces exacerbations is a new and important observation. It extends our knowledge from a previous trial of adding an ICS-LABA combination in patients already receiving tiotropium, which failed to show a significant difference in exacerbations but found benefits for secondary outcomes. ${ }^{1}$ This new evidence supports current guideline recommendations that all 3 medications should be used together in patients with COPD who have frequent exacerbations. ${ }^{23}$

At the same time, the failure of all of these trials to find significant effects on mortality or decline in $\mathrm{FEV}_{1}$ is disheartening and suggests we may have reached the limit of what can be achieved with current inhaled medications. Further progress in combating the morbidity and mortality associated with severe COPD may now require shifting our attention to new therapeutic pathways.

\section{Matthew B Stanbrook, MD, PhD}

University Health Network, University of Toronto Toronto, Ontario, Canada

1. Aaron SD, Vandemheen $\mathrm{KL}$, Fergusson D, et al. Tiotropium in combination with placebo, salmeterol, or fluticasone-salmeterol for treatment of chronic obstructive pulmonary disease: a randomized trial. Ann Intern Med 2007:146:545-55.

2. Global Initiative for Chronic Obstructive Lung Disease. Global strategy for the diagnosis, management, and prevention of COPD. November 2008. www. goldcopd.org (accessed 9 Dec 2008).

3. O'Donnell DE, Aaron S, Bourbeau J, et al. Canadian Thoracic Society recommendations for management of chronic obstructive pulmonary disease-2007 update. Can Respir J 2007:14:5B-32B. 